\title{
MAPEANDO A PESQUISA EM EDUCAÇÃO DAS RELAÇÕES ÉTNICO-RACIAIS
}

Leandra A. M. S. Rodrigues ${ }^{\mathrm{I}}$

Mayara Lustosa de Oliveira BarbosaII

Cristiane Maria Ribeiro III

I Instituto Federal de Educação, Ciência e Tecnologia Goiano, Urutaí (GO), Brasil; leandra.aparecida@hotmail.com

II Instituto Federal de Brasília (IFB), Brasília (DF), Brasil; mayara.barbosa@ifb.edu.br

III Instituto Federal de Educação, Ciência e Tecnologia Goiano, Urutaí (GO), Brasil; cristiane.maria@ifgoiano.edu.br

\section{Resumo}

O objetivo da pesquisa foi realizar uma análise bibliométrica da produção científica sobre a Educação das Relações Étnico-Raciais na base de dados Web of Science (WoS). A amostra foi composta por 2.916 artigos, publicados em 384 fontes, no período de 1945 a 2019. Eles foram exportados da base WoS para o software RStudio, onde foi utilizado o pacote Bibliometrix. Junto à perspectiva quantitativa, foi aplicada uma análise qualitativa, baseada na análise de conteúdo de Bardin, considerando os artigos mais citados dos últimos 20 anos. A principal contribuição do artigo foi oferecer informações interessantes sobre a evolução do campo em âmbito internacional, por meio de um desenho quantitativo, possibilitando aos pesquisadores o reconhecimento de possíveis lacunas na área.

\section{ANÁLISE BIBLIOMÉTRICA • RELAÇÕES ÉTNICO-RACIAIS・RACISMO}

\section{MAPPING THE STUDY ON EDUCATION OF ETHNIC-RACIAL RELATIONS \\ Abstract}

The study conducted a bibliometric analysis of the scientific production on Education of Ethnic-Racial Relations in the Web of Science (WoS) database. The sample consisted of 2,916 articles published in 384 sources from 1945 to 2019. These papers were transferred from the WoS database to the RStudio software where the Bibliometrix package was used. In addition to a quantitative perspective, a qualitative analysis was performed This analysis was based on Bardin's content analysis, considering the most cited articles in the last 20 years. The main contribution of this study was to offer interesting information about the evolution of the field in the international scope, through a quantitative design enabling researchers to recognize possible gaps in the area.

BIBLIOMETRIC ANALYSIS • ETHNIC-RACIAL RELATIONS • RACISM 


\section{MAPEO DE LA INVESTIGACIÓN EN EDUCACIÓN DE LAS RELACIONES ÉTNICO-RACIALES}

\section{Resumen}

El objetivo de esta investigación fue realizar un análisis bibliométrico de la producción científica sobre la Educación de las Relaciones Étnico-Raciales en la base de datos Web of Science (WoS). La muestra estuvo compuesta por 2.916 artículos, publicados en 384 fuentes desde 1945 hasta 2019. Estas fueron exportadas desde la base de WoS al software RStudio, donde se utilizó el paquete Bibliometrix. Desde la perspectiva cuantitativa, se aplicó un análisis cualitativo, basado en el análisis de contenido de Bardin, considerando los artículos más citados de los últimos 20 años. La principal contribución del artículo fue ofrecer informaciones interesantes sobre la evolución del campo a nivel internacional, a través de un diseño cuantitativo, que permita a los investigadores reconocer posibles brechas en el área.

ANÁLISIS BIBLIOMÉTRICO • RELACIONES ÉTNICO-RACIALES • RACISMO

\section{CARTOGRAPHIE DE LA RECHERCHE EN ÉDUCATION SUR LES RAPPORTS DE RACE ET D'ETHNIE}

\section{Résumé}

L'objectif de la recherche était de réaliser une analyse bibliométrique de la production scientifique au sujet de l'Éducations sur les rapports de race et d'ethnie dans la base de données Web of Science (WoS). L'échantillon était composé de 2916 articles, publiés entre 1945 et 2019 dans 384 sources, qui ont été ensuite exportés de la base WoS vers le logiciel RStudio, où le package Bibliometrix a été utilisé. En plus de la perspective quantitative, une analyse qualitative, basée sur l'analyse de contenu de Bardin, a été réalisée considérant les articles les plus cités au cours des 20 dernières années. Grâce à sa conception quantitative, la contribution la plus importante de cet article a été de fournir des informations intéressantes sur l'évolution du champ d'études à l'échelle internationale, permettant aux chercheurs d'identifier d'éventuelles lacunes dans le domaine.

ANALYSE BIBLIOMÉTRIQUE・RELATIONS ETHNO-RACIALES • RACISME 
IVERSAS DENÚNCIAS APONTAM PARA AS PIORES CONDIÇÕES DE VIDA DOS NEGROS NO BRASIL, bem como para as consequências que a desigualdade e a discriminação produzem não apenas para esse grupo específico, mas para a sociedade como um todo (Faedo et al., 2017).

Segundo aponta Silvério (2002), apenas no século XX foi de fato travada a intensa batalha pela inclusão e tratamento igualitário à população negra, ao mesmo tempo que eram repudiadas todas as formas de discriminação, primando-se pelo respeito às particularidades e diferenças culturais. O movimento negro se destacou como agente coletivo e político das ações, conquistando alguns avanços, os quais incluem o enquadramento do racismo como crime inafiançável e o estabelecimento, nas diretrizes e bases para a educação nacional, de currículos com conteúdos relacionados à história e cultura afro-brasileira (Gomes, 2012).

A partir de tais ações, percebeu-se um crescente interesse em pesquisas na área das relações étnico-raciais, com picos registrados entre 2010 e 2012 (Silva et al., 2018). Entretanto, é sabido que o aumento exponencial na publicação de pesquisas científicas nem sempre representa uma aplicação imediata ou eficaz das descobertas. Isso é especialmente evidente no que diz respeito à educação, em que a lacuna entre a pesquisa e a prática é ainda mais evidente (Lawlor et al., 2019).

Assim, apesar de inúmeras pesquisas apontarem a necessidade de desenvolvimento e adoção de métodos de ensino baseados em evidências, de modo a promover a efetiva implementação da Educação das Relações Étnico-Raciais (Erer) (Gomes \& Jesus, 2013; Paula \& Guimarães, 2014; Dias \& Cecatto, 2015; Marques, 2017), bem como a necessidade de formação adequada para que docentes estejam melhor capacitados para a lida com a temática em sala de aula (Pereira et al., 2018; Guimarães, 2015; Gillam, 2016), a lacuna entre a pesquisa e a aplicação prática se mantém em ambas as áreas.

Uma das justificativas apontadas para a lacuna apresentada é o parco diálogo entre a escola e a universidade, o que muitas vezes dificulta o acesso de docentes a práticas instrucionais atuais e a outras pesquisas relevantes na área (Müller \& Coelho, 2013; Coelho \& Soares, 2017). Tendo em vista o fato de que a maior parte dos pesquisadores e grupos de pesquisa na área da educação é composta por docentes universitários, é de extrema importância que professores da educação básica acessem o conhecimento produzido dentro dos muros dessas instituições.

Sabendo que as publicações científicas, tais como artigos revisados por pares, são as formas mais seguras de acesso à informação validada nas mais diversas áreas do conhecimento, é lógico concluir que a divulgação de dados contidos em tais documentos pode auxiliar tanto na redução da lacuna entre pesquisa e prática quanto na aproximação de propostas instrucionais baseadas em evidências da sala de aula.

Dessa forma, é de extrema relevância atuar em busca de uma sistematização das publicações na área da Erer, de modo a facilitar a divulgação científica das pesquisas com maior impacto e revelar resultados mais proeminentes para aplicação por parte de docentes e pesquisadores da área. Afinal, os professores são elementos-chave na construção de escolas com propostas inclusivas, as quais, por sua vez, são os meios mais eficazes para reduzir o preconceito, combater atitudes discriminatórias e, em última instância, levar à criação de uma sociedade mais receptiva (Booth \& Ainscow, 2011).

Um método de levantamento que permite a divulgação de propostas com maior impacto em determinadas áreas de pesquisa, e que tem se mostrado uma alternativa consistente com as pesquisas atuais na educação é a condução de análises bibliométricas (Huang et al., 2019; Hernández-Torrano et al., 2020). Assim, o presente estudo intenta contribuir com a área da Erer, 
realizando uma análise bibliométrica da produção científica sobre a temática, na base de dados Web of Science (WoS).

Além da análise quantitativa, foi intuito das pesquisadoras incluir uma análise qualitativa dos artigos internacionalmente mais citados nos últimos 20 anos. Assim, depois de apresentar a trajetória de crescimento da produção na área - considerando: 1) as redes de pesquisa colaborativa; 2) países que mais publicaram; 3) redes de cocitação -, foi conduzida uma análise de conteúdo (Bardin, 2011) dos artigos mais citados ao longo dos últimos 20 anos, de modo a identificar e divulgar, por meio do agrupamento em categorias, o foco dos trabalhos com maior impacto recentemente.

O período de 20 anos não foi estabelecido de modo arbitrário: além de considerar estudos mais atuais para a análise de conteúdo, a definição do período também tem em vista marcos internacionais que estimularam pesquisas e investimentos na área. $\mathrm{O}$ primeiro marco trata-se da III Conferência Mundial contra o Racismo, Discriminação Racial, Xenofobia e Intolerância Correlata, realizada pela Organização das Nações Unidas (ONU), em 2001, a qual conferiu visibilidade internacional à situação dos afrodescendentes e resultou na Declaração e no Programa de Ação de Durban, instrumentos jurídicos de que o Brasil é um dos signatários, os quais amparam o cumprimento dos direitos humanos e ratificam políticas de igualdade racial (Gomes \& Miranda, 2018).

Outros marcos ocorreram em década mais recente, a saber, a reunião internacional para a revisão da Declaração e do Programa de Ação, intitulada Durban + 10, realizada em 2011, e a Resolução n. 68/237, de 23 de dezembro de 2013, estruturada na Assembleia Geral da ONU, a qual proclamou a Década Internacional de Afrodescendentes, com início em $1^{\circ}$ de janeiro de 2015 e fim em 31 de dezembro de 2024, ambos visando a instar os Estados-Membros e demais países à superação do racismo (Gomes \& Miranda, 2018).

\section{Procedimentos metodológicos}

\section{Caracterização da pesquisa}

A presente pesquisa é descritiva-exploratória (Gerhardt \& Silveira, 2009) e utilizou a abordagem bibliométrica para revisar a literatura nacional e internacional relacionada à Erer, fazendo uso de metadados extraídos do banco de dados da base WoS. Por definição, a bibliometria é uma técnica quantitativa e estatística de medição dos índices de produção e disseminação do conhecimento científico em determinada área do conhecimento (Huang et al., 2019).

\section{Levantamento e análise dos dados}

De modo a obter um levantamento abrangente da literatura, foi realizada uma pesquisa na base WoS. A referida base foi escolhida por possuir uma amplitude relevante de cobertura, visto que não apenas reúne mais de 9.000 periódicos internacionais considerados mais relevantes nas áreas de ciências puras, sociais, aplicadas e médicas, mas também permite acesso a trabalhos publicados desde 1945 (Ribeiro et al., 2007). Além disso, a WoS usa uma medida internacionalmente aceita de avaliação de periódicos, sendo a principal fonte de dados usada para obter indicadores bibliográficos, e alcançando um status de autoridade na identificação de periódicos de alta qualidade globalmente (Rafols et al., 2016; Testa, 2015).

Além dos aspectos citados, a escolha da base deu-se porque, diferentemente de outras bases amplas, nacionais e internacionais, ela tem categorias relacionadas à educação delimitadas. Afora isso, por meio dela é possível exportar separadamente os dados dos arquivos (título, resumo, palavras-chave, etc.) para uma análise mais detalhada. Infelizmente, as bases nacionais mais 
amplas não oferecem as mesmas ferramentas para a retirada e análise desses dados. Apesar de nosso levantamento não conter um grande volume de pesquisas em português, ressalta-se que a WoS também possibilitou o acesso a artigos nacionais, publicados em revistas conceituadas, como será possível verificar pelos resultados da pesquisa.

Os descritores utilizados para a busca foram selecionados tendo como base o Thesaurus da Educação Brasileira do Instituto Nacional de Estudos e Pesquisas Educacionais Anísio Teixeira (Inep, 2020) e o Thesaurus da Educação Internacional, disponibilizado pela Organização das Nações Unidas para a Educação, a Ciência e a Cultura (Unesco, 2020). Assim, em ambas as fontes foram buscados todos os descritores relacionados à questão étnico-racial e à educação. Após a seleção dos descritores, foram aplicados à fórmula de busca na base os operadores boolianos "and" e "or", de modo a tornar a pesquisa mais completa e abrangente possível.

Ressalta-se que: 1) a pesquisa na base é feita em língua inglesa; 2) a busca selecionou todas as publicações desde 1945, ano inicial da base, até 2019; 3) a busca foi realizada utilizando-se a ferramenta de pesquisa avançada - assim, a adição do item "TS" antes da fórmula indica que os descritores podem ser encontrados no título, no resumo ou nas palavras-chave do artigo.

Dado o exposto, segue a fórmula com cada um dos termos utilizados: $T S=$ (race relations $A N D$ education) $O R$ (racial prejudice $A N D$ education) $O R$ (racial segregation $A N D$ education) $O R$ (racial discrimination AND education) OR (racism AND education) OR (racial conflicts $A N D$ education) OR (African descendants AND education) OR (black people AND education) OR (blacks $A N D$ access $A N D$ education) OR (Afro-descendants $A N D$ education) OR (blacks AND educational opportunities) OR (blacks AND educational discrimination) OR (blacks AND Racial identity) OR (blacks AND racialpolicy).

Após a pesquisa, foram encontradas 11.986 publicações, as quais incluem capítulos de livros e trabalhos publicados em anais de eventos e artigos. Seguiu-se a etapa de aplicação dos critérios de inclusão e exclusão dos trabalhos. Em nosso caso, os critérios de inclusão foram: 1) somente artigos científicos revisados por pares em revistas indexadas na base WoS; e 2) artigos incluídos nas três categorias relacionadas à educação ou estudos étnicos da base, a saber, "Education Educational Research", "Ethnic Studies" e "Education Scientific Disciplines". Dessa forma, foram selecionados 2.916 artigos.

\section{Análise quantitativa}

Com relação à abordagem da pesquisa, optou-se pela utilização do método misto, o qual consiste na coleta, análise e combinação de técnicas quantitativas e qualitativas em um mesmo desenho de pesquisa, de modo a obter uma compreensão mais profunda do tema ou objeto em estudo (Creswell \& Plano-Clark, 2011).

Estatística descritiva foi aplicada para apresentação dos resultados quantitativos dos 2.916 artigos cobertos pela base no período de busca. Reforça-se que, para obtenção e análise de tais dados, todos os arquivos encontrados foram exportados da base WoS para o software RStudio, em que foi utilizado o pacote Bibliometrix (Aria \& Curccurullo, 2017) para levantamento das características pretendidas, a saber: 1) quantos artigos foram publicados por ano e qual a taxa média de crescimento anual; 2) quais as redes de colaboração e cocitação; e 3) quais os artigos mais citados nos últimos 20 anos.

Vale pontuar que, para obter os gráficos das figuras 3, 4 e 5, foi utilizada a ferramenta Biblioshiny, um aplicativo acessado por meio do software RStudio, o qual fornece uma interface web para o manejo dos dados do pacote Bibliometrix, permitindo a combinação dos dados disponíveis na base, de modo a identificar, entre outras informações, as redes de colaboração e cocitação entre os autores, assim como os principais temas pesquisados ao longo dos anos. 


\section{Análise qualitativa}

Junto à perspectiva quantitativa, a partir dos artigos mais citados na área, apresentou-se um panorama da evolução temática da pesquisa no campo. Posteriormente, foi aplicada a análise de conteúdo a 50 artigos, de modo a apresentar, por meio da estruturação de categorias, as principais áreas de pesquisa dos artigos mais citados (Bardin, 2011).

Para tanto, inicialmente foram listados os 100 artigos mais citados encontrados na base. Desses, foram incluídos na análise apenas aqueles publicados nos últimos 20 anos, totalizando 77 artigos. Para a pré-análise dos dados, fez-se, primeiramente, uma leitura dos resumos das publicações, de modo a verificar a importância de sua inclusão no corpus da pesquisa. Assim, seguindo a regra da pertinência, foram excluídos artigos que apenas tangenciavam a questão racial, tendo foco em temas como religião, linguagem e questões de gênero. Restaram, então, apenas 50 publicações.

Posteriormente, foram feitos a leitura e o fichamento dos 50 artigos selecionados, tabulando o título, os autores, o ano de publicação, os objetivos e as principais conclusões. Após o processo, os artigos foram codificados numericamente, e então selecionadas unidades de codificação, de modo a permitir a agregação em função de características em comum, para então serem estabelecidas as categorias, as quais são apresentadas nos resultados. Vale ressaltar que o processo de categorização passou por dupla validação, tendo sido feito de modo individual por duas pesquisadoras e validado posteriormente em análise cruzada, a fim de diminuir a possibilidade de subjetividade no processo de análise.

\section{Resultados e discussão}

\section{Crescimento da pesquisa na área, países que mais publicaram, redes de colaboração e cocitação}

Foram encontrados 2.916 artigos publicados em 384 fontes ao longo de 62 anos considerados na pesquisa, visto que o primeiro artigo sobre a temática foi publicado na base em 1957. No gráfico da Figura 1, é possível verificar a quantidade de publicações anuais. A taxa de crescimento anual de pesquisas na área é de 7,43\%, sendo que mais de $90 \%$ da produção está concentrada após o ano de 1990, ou seja, nos últimos 30 anos.

\section{FIGURA 1}

Número de trabalhos publicados na base Web of Science - 1957 a 2019

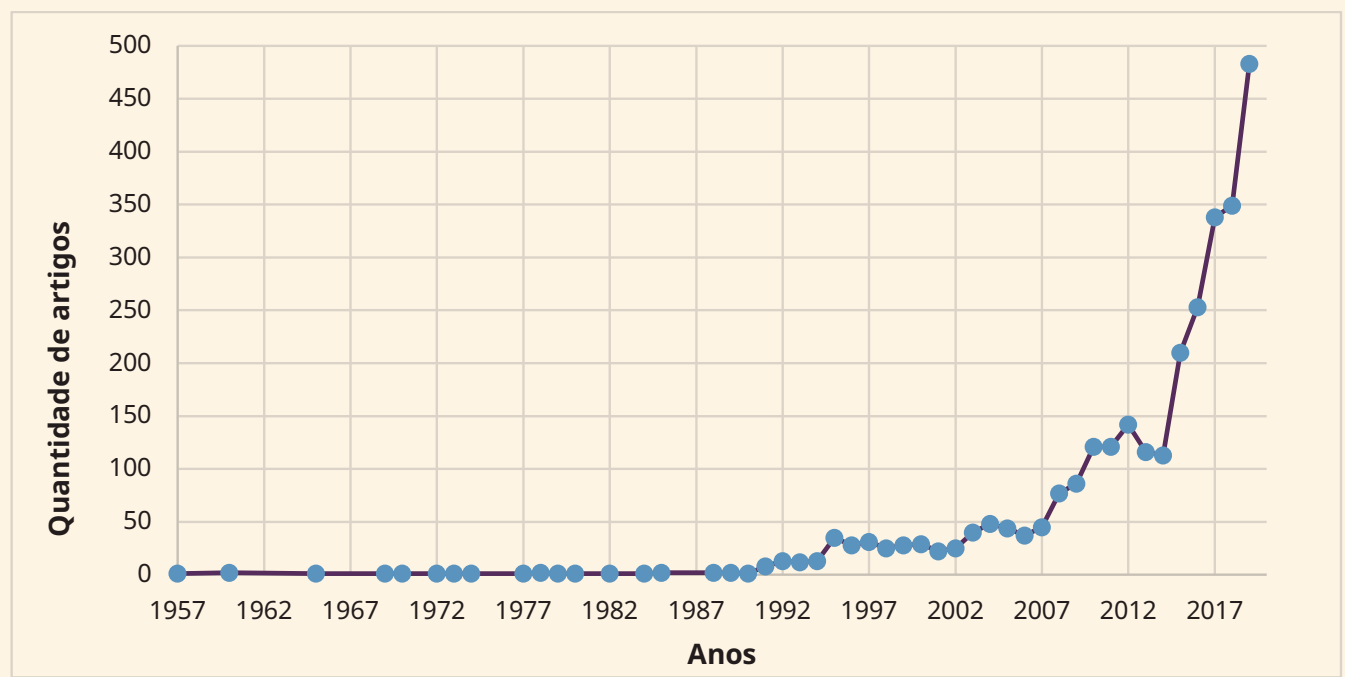


Como é possível observar na Figura 2, o Brasil aparece como o quarto país com maior número de publicações na área. Entretanto, tem-se percebido que o crescimento numérico expressivo nas publicações não tem sido acompanhado por um aumento correspondente na internacionalização da ciência no país (Ramos, 2018). Assim, vale destacar que, embora o Brasil esteja em quarto lugar no número de publicações na área pesquisada, é também o país com menor proporção de cooperação na publicação de artigos com autores de múltiplos países entre os 10 que mais publicam.

FIGURA 2

Países que mais publicaram artigos sobre o tema pesquisado - 1957 a 2019

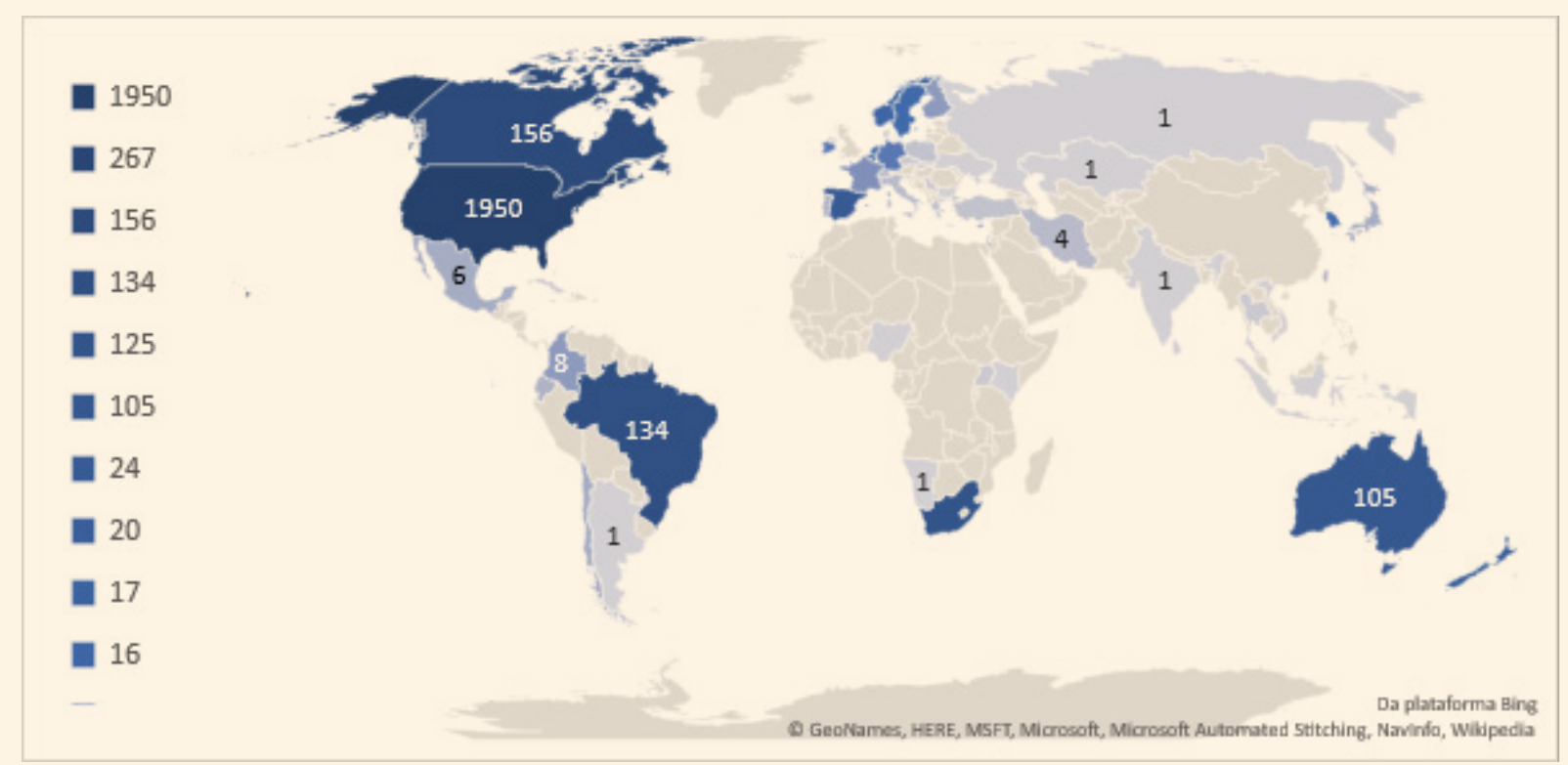

Nota: Os 10 mais produtivos foram: Estados Unidos (1950), Inglaterra (267), Canadá (156), Brasil (134), África do Sul (125), Austrália (105), Espanha (24), Nova Zelândia (20), Bélgica (17) e Noruega (16).

Fonte: Elaborado pelas autoras com Excel.

A Espanha lidera o ranking como o país que mais estabelece cooperação internacional proporcionalmente em pesquisas na área - sendo que $19 \%$ das produções são artigos com autores de múltiplos países -, seguida pela Bélgica (18,8\%), Canadá (16,3\%), Austrália (15,8\%), África do Sul (12\%), Reino Unido (11,2\%), Estados Unidos da América (7,8\%), Nova Zelândia (5,8\%), Noruega (5,3\%) e, por último, o Brasil, com apenas $2,5 \%$ das publicações.

Outro dado que merece destaque são as redes de colaboração entre os autores, as quais são apresentadas na Figura 3. Somente os 50 autores com mais publicações no conjunto de dados foram considerados. Vale ressaltar que autores sem vínculos com outros no conjunto foram excluídos do mapa, totalizando 25 autores representados. Cada um dos clusters pode ser interpretado como um grupo de pesquisa relativamente formal, composto por um número variável de autores que foram coautores entre si. Ressalta-se que podem ser expostos também colaboradores eventuais. $\mathrm{O}$ tamanho dos quadros demonstra um maior número de publicações daquele autor. 
FIGURA 3

Rede de colaboração entre os 25 autores que mais publicaram

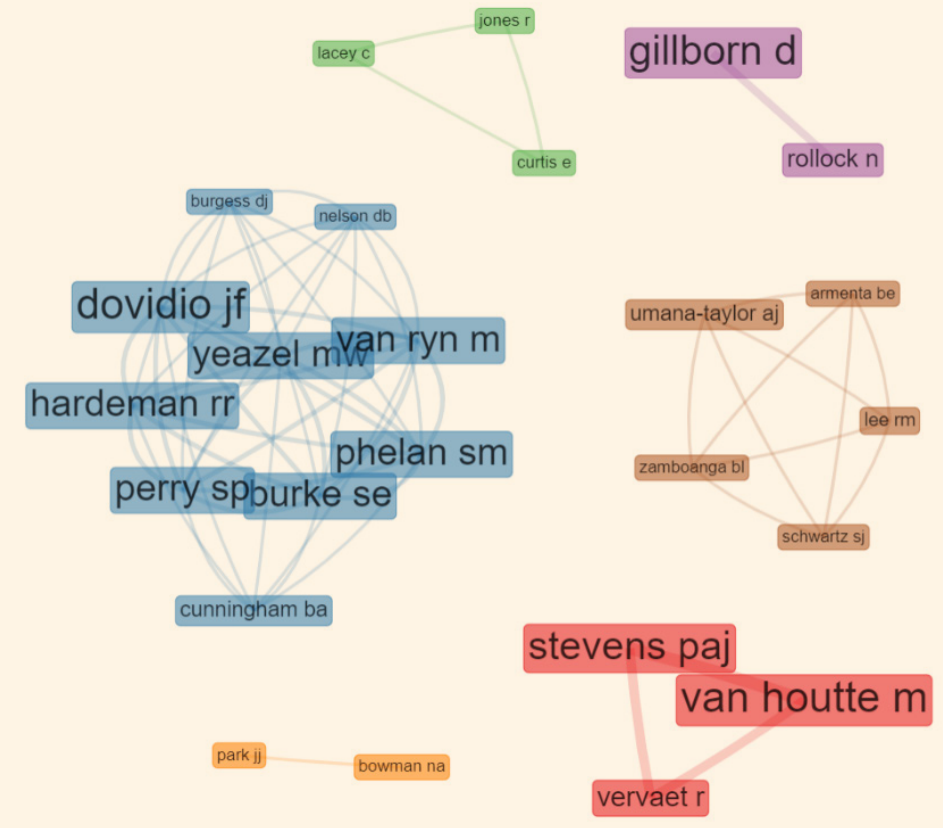

Fonte: Elaborado pelas autoras com Biblioshiny.

Os dados da Figura 3 foram obtidos por meio do software Biblioshiny (versão on-line do pacote Bibliometrix), utilizando o algoritmo de cluster Louvain. Foram mantidos somente aqueles que possuíam uma ou mais conexões.

O cluster azul destaca-se como o maior grupo de colaboradores e o mais equilibrado em termos de produção. A mais recente produção desse grupo não está diretamente relacionada com os ambientes de ensino. Embora possua um viés educativo, a pesquisa tem como objetivo apresentar o valor do contato inter-racial para reduzir o viés, chamado pelos autores de "antipreto", entre médicos não negros (Onyeador et al., 2019).

A colaboração mais recente, que conta com a presença dos autores Cunningham e Yeazel, está mais associada ao contexto educacional e avalia os efeitos do racismo na educação médica, especialmente nas decisões dos estudantes de praticar a profissão em comunidades carentes ou minoritárias (Phelan et al., 2019).

No cluster marrom, quatro autores estabelecem colaboração com Adriana J. Umaña-Taylor, em um grupo com menos publicações, mas que é o segundo maior número de pesquisadores envolvidos. Uma de suas produções examina as associações entre percepções de discriminação de grupos étnicos e sintomas depressivos entre 2.315 estudantes de minorias étnicas (Brittian et al., 2015).

Outro cluster que chama atenção pelo número de publicações dos pesquisadores participantes é o vermelho. A colaboração mais atual desse grupo tem como objetivo investigar a associação entre a composição étnica na escola e o preconceito étnico dos professores (Vervaet et al., 2016).

No cluster roxo, destaca-se o nome de Gillborn, o pesquisador que mais contribuiu com publicações na área desde 1957. O docente estabelece uma relação estreita, em termos de colaboração em publicações, com apenas um colega, o professor Nicola Rollock. A colaboração mais recente entre os autores resultou no maior estudo qualitativo da relação entre a educação e a classe média negra já realizado no Reino Unido. O artigo enfoca as interações dos pais com os professores de seus filhos e apresenta, em particular, o fato de que os professores tendem a ter expectativas acadêmicas mais baixas em relação às crianças negras (Gillborn et al., 2012). 
Com relação às redes de cocitação, foi estruturado o cluster da Figura 4, na qual os 50 trabalhos mais citados, com um mínimo de 10 conexões entre eles, foram selecionados. Na figura, é possível identificar cinco clusters com certa definição, sendo que os trabalhos mais citados aparecem em caixas maiores. A seguir, faremos uma síntese dos trabalhos que mais se destacam nos clusters mais representativos, revelando o possível tema direcionador desses agrupamentos.

FIGURA 4

Rede de cocitação revelando clusters relativamente bem estabelecidos, com relação às citações

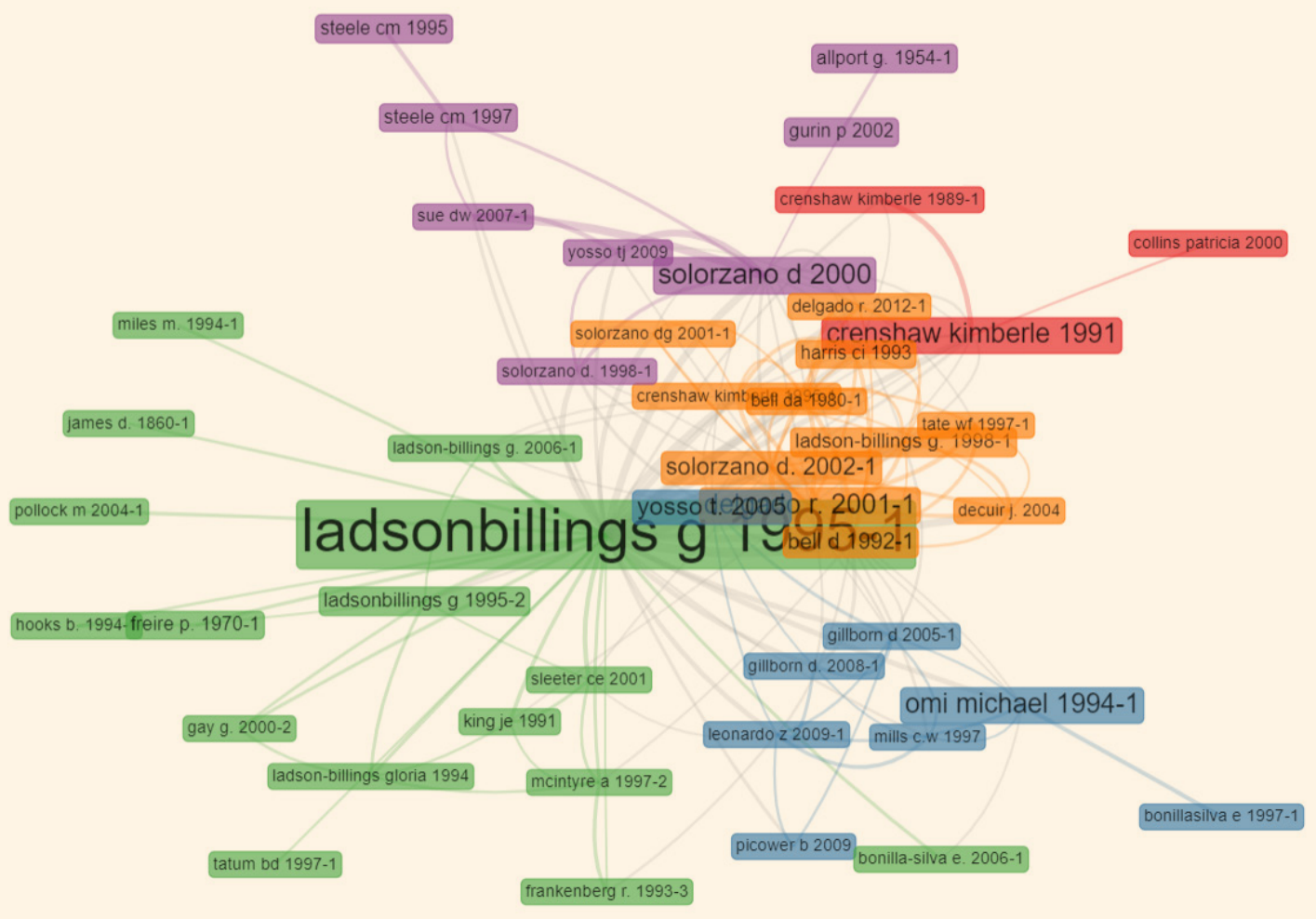

Fonte: Elaborado pelas autoras com Biblioshiny.

Quanto mais citado o trabalho, maior o quadro representando sua referência.

O cluster verde destaca o trabalho de Ladson-Billings e Tate (1995), um dos clássicos na área. Esse artigo apresentou a Teoria Racial Crítica (TRC) para a comunidade de pesquisadores da educação. $\mathrm{O}$ artigo defende uma perspectiva teórica da raça crítica na educação, análoga à da TRC nos estudos jurídicos, desenvolvendo três ações: 1) a raça continua sendo significativa nos Estados Unidos; 2) a sociedade norte-americana se baseia nos direitos de propriedade e não nos direitos humanos; e 3) a interseção de raça e propriedade cria uma ferramenta analítica para entender a desigualdade. Os autores concluem com uma análise das limitações do paradigma multicultural da época.

Por estarem muito próximos entre si, os principais autores dos clusters verde e laranja tangenciam o tema abordado nas pesquisas. Tal fato pode ser comprovado ao se analisar o trabalho de Delgado (2001), o qual surge em destaque no cluster laranja. Contudo, embora também aborde a TRC, seu objetivo é apontar que teorias idealistas que explicam a dinâmica racial em termos de pensamentos, palavras e impulsos internos são analiticamente incompletas, e que cuidar do lado material da raça e do racismo confere uma série de benefícios, ao mesmo tempo que evita inúmeras desvantagens associadas à abordagem idealista. 
No cluster roxo, o trabalho de Solorzano et al. (2000) aparece como um dos mais citados; nele se demonstra como microagressões podem afetar o desempenho dos alunos negros. $\mathrm{O}$ autor define as microagressões como insultos sutis (verbais, não verbais e/ou visuais) direcionados a pessoas negras, de forma geralmente automática ou inconsciente. Usando a TRC, o estudo fornece um exame das microagressões raciais e revela seu impacto negativo sobre estudantes afro-americanos.

Por estar mais afastado do centro em que se concentram os demais clusters, o cluster azul revela uma temática mais distante da proposta pelos demais autores. O destaque do grupo é dado ao livro de Michael Omi e Howard Winant (1994), o qual apresenta outra teoria, a da formação racial, como uma ferramenta analítica que descreve a raça como uma identidade socialmente construída, na qual o conteúdo e a importância das categorias raciais são determinados por forças sociais, econômicas e políticas.

Outro ponto que merece atenção é a evolução temática dos trabalhos ao longo dos anos. Tal dado foi gerado a partir das palavras-chave utilizadas nos artigos e representado no gráfico da Figura 5. Nele é possível observar como os estudos na área foram adquirindo focos variados ao longo dos anos, bem como os tópicos de tendências mais recentes. Embora o período de busca caracterizado tenha sido de 1957, data da primeira publicação na área, ao se estabelecer como critério de busca palavras que houvessem aparecido pelo menos em cinco publicações de cada ano, o gráfico aponta dados somente a partir de 2006. Isso porque só recentemente a área de pesquisa na educação ganhou maior volume em termos de publicações.

\section{FIGURA 5}

Tópicos de tendência ao longo dos anos com base nas palavras-chaves

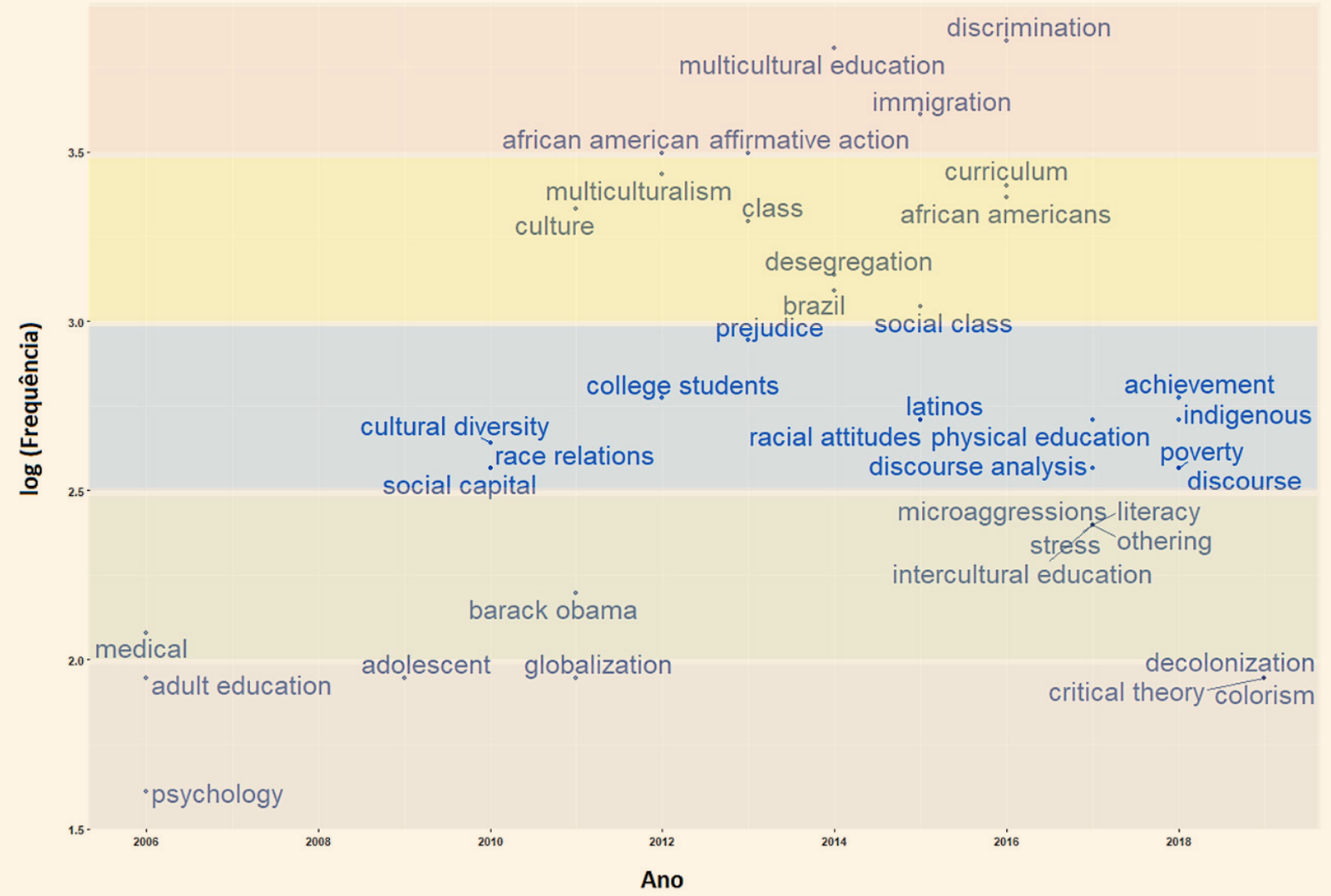

Fonte: Elaborado pelas autoras com Biblioshiny.

Com relação à análise dos temas, as linhas coloridas indicam a frequência com que os termos apareceram ao longo dos anos, os quais estão indicados no eixo "x" do gráfico. Na linha 
cinza, a frequência dos temas é mais baixa; porém, se seguirmos para o fim da linha, encontraremos temas mais atuais, entre os quais merecem destaque a descolonização, a teoria crítica e o colorismo. Com relação à descolonização, podemos destacar o trabalho de Gomes (2012), no qual a autora aponta que a descolonização dos currículos na educação básica e superior exige mudanças de representação, de práticas e questionamento dos lugares de poder, sendo necessária a indagação sobre a relação entre direitos e privilégios arraigada nas escolas e na própria universidade. Embora apareça com baixa frequência, percebe-se que o tema é atual e relevante e que tais medidas devem ser colocadas em prática, de modo a se alcançar mudanças realmente efetivas na sociedade.

A TRC, por sua vez, embora tenha recebido destaque em publicações recentes, aparece com mais frequência em publicações mais antigas e elenca discussões como parte de um movimento contra o poder racial branco, sendo um tópico necessário para pesquisadores interessados no fim da supremacia branca e na elevação da ciência dos direitos humanos e da igualdade (Case \& Hemmings, 2005; Zuberi, 2016).

As pesquisas que tratam diretamente do colorismo (pigmentocracia) ainda são incipientes na literatura, tendo em vista que o tema central - evidenciar a cor de pele como forma de discriminação - é abordado de maneira tangencial em vários outros trabalhos. Seu destaque atual, ainda que com uma frequência baixa, pode ser justificado pelas palavras de Silva (2017), o qual aponta que, mesmo que o racismo exista como forma de discriminação baseada em diferenças étnicas, o colorismo permanece delimitando-se como uma maneira de exclusão social que considera as diferentes tonalidades de pele, segregando os que possuem uma tonalidade da pele mais escura.

Subindo a análise do gráfico (Figura 5), os tópicos mais frequentes e atuais que aparecem na linha verde são as microagressões e educação intercultural. Reflexões sobre microagressões raciais são de extrema importância e demonstram como eventos racistas cotidianos fortificam o racismo institucionalizado. Os autores que analisam as microagressões apontam que as ideologias de supremacia branca se valem desse comportamento para fortalecer a superioridade de um grupo dominante sobre grupos não dominantes (Gershenson et al., 2016; Huber \& Solorzano, 2015).

O termo educação intercultural surge em uma ascendente no gráfico, e sua proximidade com a palavra-chave "microagressões" sugere uma relação, tendo em vista que esse tipo de proposta educativa vem ao encontro da transformação necessária no comportamento que alimenta as microagressões. A educação intercultural é uma questão relevante quando se pensa em relações raciais e garantia de uma educação igualitária, pois proporciona o diálogo e a negociação de conflitos, respeita a identidade cultural e oferta uma educação relevante e de qualidade para todos (Unesco, 2006).

$\mathrm{Na}$ Figura 5, a faixa azul na região central do gráfico contém uma quantidade maior de palavras-chave, as quais estão concentradas após o ano de 2010. Tópicos como a diversidade cultural, atitudes raciais e preconceito se destacam pela frequência em que aparecem ao longo dos anos. Discutir a diversidade cultural é um assunto de relevância em todo o mundo, e tem se tornado um tópico de tendência. Pesquisadores da área apresentam o alerta de que é preciso manter as discussões em torno dessa agenda, visto que só assim acontecerá uma educação no contexto de reconhecimento das diferenças e a luta contra os preconceitos raciais (Denson \& Chang, 2009; Munanga, 2010). Com relação ao preconceito, pesquisas que visem a compreender como ele se desenvolve são extremamente relevantes e ainda incipientes, pois estudos indicam que muitas pessoas, embora reconheçam a existência de racismo, não se consideram preconceituosas (Sacco et al., 2016).

Nesse mesmo sentido, a literatura também aponta que refletir sobre as atitudes raciais é de fundamental importância para o progresso das discussões sobre a temática, pois, para que se alcancem mudanças institucionais abrangentes - por exemplo, no currículo, no material didático, nas metodologias de ensino, nas percepções dos professores -, é preciso mudança na formação de hábitos e nas atitudes globais e pessoais (Munanga, 2010). 
Com relação às duas últimas linhas, os tópicos apresentados são os mais regulares e bastante atuais, tendo em vista o posicionamento no gráfico. A linha amarela apresenta com frequência discussões sobre o multiculturalismo. Reflexões sobre o multiculturalismo pretendem contribuir para o desenvolvimento de uma educação valorizadora da diversidade cultural e questionadora das diferenças (Lewis, 2001) e, tendo em vista os conflitos frequentes e atuais em países como Estados Unidos, África do Sul e Mianmar, é possível que a temática seja ainda mais explorada com vistas a superar posturas dogmáticas, que congelam as identidades e desconhecem as diferenças. Ademais, como aponta a literatura, o multiculturalismo envolve justamente um posicionamento contra a opressão e a discriminação de grupos minoritários (Canen, 2007), além de compreender ações politicamente comprometidas com a justiça racial (Moreira \& Candau, 2008).

Embora não com tanta frequência, vale ressaltar que as pesquisas também mencionam o tópico "Brazil" com frequência no ano de 2014. Novaes et al. (2020), em seu estudo sobre o "estado da arte" em relações étnico-raciais e educação nas produções acadêmicas, confirmou uma produção significativa sobre as garantias legais conquistadas pelos movimentos sociais negros e a importância das ações afirmativas para a comunidade negra no período de 2013 a 2017, o que, em hipótese, poderia justificar o aumento da produção científica sobre a temática em 2014 e seu aparecimento na linha amarela.

$\mathrm{Na}$ linha rosa, entre os temas mais frequentes, destacam-se a educação multicultural e as ações afirmativas. $\mathrm{O}$ já mencionado multiculturalismo se reafirma nos tópicos mais frequentes e atuais, confirmando a existência constante de reflexões sobre uma educação valorizadora da diversidade (Canen, 2007). Com relação às ações afirmativas, elas têm adquirido cada vez mais espaço na educação com intuito de diminuir as discrepâncias existentes entre grupos raciais (Rodrigues et al., 2021) e são de fundamental importância para o processo de valorização da diversidade no contexto escolar, tendo em vista o fato de que analisam o conjunto de políticas públicas e privadas que visam a combater a discriminação racial e corrigir ou aplacar os efeitos de uma discriminação histórica (Gomes, 2001).

As discussões nesse sentido assumem um papel frente à democratização do acesso e à permanência de estudantes negros nas escolas e na universidade (Passos, 2015; Rodrigues et al., 2021), bem como analisam a consolidação das ações afirmativas para a melhoria da desigualdade e a superação do apartheid informal presente na sociedade (Clève, 2016), sendo, portanto, uma temática que ainda deve ser encontrada em pesquisas recentes.

Estudos frequentes têm evidenciado as discussões das temáticas supracitadas, revelando que são linhas mais proeminentes de interpelação da temática das relações étnico-raciais (Arroyo, 2010; Carvalho, 2014; Abramowicz \& Rodrigues, 2014; Candau, 2011; Rodrigues et al., 2021).

\section{Descrição dos dados dos artigos selecionados para a análise de conteúdo}

Apesar de os tópicos de tendência (Figura 5) apontarem para assuntos que se repetiram em artigos publicados no período indicado, eles podem não refletir propriamente o conteúdo dos artigos de maior impacto da área. Assim, sabendo que mais de $90 \%$ da produção analisada está concentrada após a década de 1990, foi utilizado um recorte desse período e, a partir dos 50 artigos mais citados dos últimos 20 anos (Quadro 1), foi conduzida sua categorização pelo aspecto temático (Bardin, 2011). Dessa forma, os textos foram agrupados de acordo com a temática discutida na pesquisa, de modo a apresentar as principais áreas de investigação dos artigos mais citados, os quais estão codificados no Quadro 2 e ordenados a partir do mais atual (2016) ao mais antigo (2000). 
QUADRO 1

Referências dos textos incluídos na análise de conteúdo em ordem cronológica partindo do mais atual

\begin{tabular}{|c|c|c|c|}
\hline \multicolumn{4}{|c|}{ Referências dos artigos analisados } \\
\hline 1 & Gershenson et al. (2016) & 26 & Milner Iv (2008) \\
\hline 2 & Huber e Solorzano (2015) & 27 & Vaught e Castagno (2008) \\
\hline 3 & Gutiérrez (2013) & 28 & Haviland (2008) \\
\hline 4 & Spaull (2013) & 29 & Harper e Quaye (2007) \\
\hline 5 & Harper (2012) & 30 & Stanley (2006) \\
\hline 6 & Logan et al. (2012) & 31 & Dougherty e Kienzl (2006) \\
\hline 7 & Kohli e Solórzano (2012) & 32 & Saporito e Sohoni (2006) \\
\hline 8 & McGuinn (2012) & 33 & Rolón-Dow (2005) \\
\hline 9 & Ready e Wright (2011) & 34 & Case e Hemmings (2005) \\
\hline 10 & McGee e Martin (2011) & 35 & Bonilla-Silva (2004) \\
\hline 11 & Bowman (2011) & 36 & Goldsmith (2004) \\
\hline 12 & Buras (2011) & 37 & Farkas (2003) \\
\hline 13 & Gregory et al. (2011) & 38 & Verkuyten e Thijs (2002) \\
\hline 14 & Benner e Crosnoe (2011) & 39 & Fries-Britt e Turner (2002) \\
\hline 15 & Gregory et al. (2010) & 40 & Constantine e Blackmon (2002) \\
\hline 16 & Leonardo e Porter (2010) & 41 & Telles (2002) \\
\hline 17 & Bowman (2010) & 42 & Johnson (2002) \\
\hline 18 & Young (2010) & 43 & Lewis (2001) \\
\hline 19 & Picower (2009) & 44 & Solorzano et al. (2000) \\
\hline 20 & Abrams e Moio (2009) & 45 & Williams e Williams-Morris (2000) \\
\hline 21 & Sue et al. (2009) & 46 & Ladson-Billings (2000) \\
\hline 22 & Hughes et al. (2009) & 47 & Merryfield (2000) \\
\hline 23 & Denson e Chang (2009) & 48 & Cochran-Smith (2000) \\
\hline 24 & Cooper (2009) & 49 & Epstein (1998) \\
\hline 25 & Gasman e Palmer (2008) & 50 & Allen et al. (2000) \\
\hline
\end{tabular}

Fonte: Elaborado pelas autoras (2020).

$\mathrm{Na}$ análise das informações, seguindo mais uma etapa da análise de conteúdo (Bardin, 2011), estabeleceram-se 10 categorias a posteriori, conforme apresentadas no Quadro 2. Ressalta-se que, para a apresentação da categorização, usou-se a codificação feita no Quadro 1.

QUADRO 2

Definições das categorias, códigos dos artigos incluídos em cada uma e quantidade total de artigos

\begin{tabular}{|c|c|c|}
\hline CATEGORIAS & ARTIGOS & TOTAL \\
\hline $\begin{array}{c}1 \text { - Diferenças raciais, demográficas e econômicas afetam o desempenho e a saúde } \\
\text { mental do aluno, bem como sua relação com o professor }\end{array}$ & $\begin{array}{l}4 ; 6 ; 10 ; 13 ; 14 ; 15 ; 31 ; 32 \\
35 ; 40 ; 45\end{array}$ & 11 \\
\hline $\begin{array}{l}2 \text { - Teoria Racial Crítica para analisar raça, racismo, práticas pedagógicas, aspectos } \\
\text { sociais e microagressões }\end{array}$ & $2 ; 3 ; 5 ; 7 ; 20 ; 33 ; 44$ & 7 \\
\hline 3 - Política educacional para a melhoria da educação e das relações raciais & $8 ; 12$ & 2 \\
\hline $\begin{array}{l}4 \text { - Formação de professores para a valorização da diversidade e melhoria das } \\
\text { relações raciais }\end{array}$ & $\begin{array}{l}18 ; 19 ; 21 ; 24 ; 26 ; 27 ; 30 \\
\quad 34 ; 39 ; 42 ; 46 ; 47 ; 48\end{array}$ & 13 \\
\hline
\end{tabular}




\begin{tabular}{|c|c|c|}
\hline CATEGORIAS & ARTIGOS & TOTAL \\
\hline $\begin{array}{c}5 \text { - Reconhecimento da diversidade racial e cultural melhora o desempenho e o } \\
\text { engajamento dos estudantes negros }\end{array}$ & $11 ; 17 ; 22 ; 23 ; 43 ; 49$ & 6 \\
\hline 6 - Naturalização do preconceito e falta de diálogo sobre as relações raciais & 16 & 1 \\
\hline $\begin{array}{l}7 \text { - Importância das faculdades e universidades historicamente negras (HBCU') para } \\
\text { a formação dos alunos negros }\end{array}$ & 25 & 1 \\
\hline $\begin{array}{l}8 \text { - Representação e postura de professores (brancos e negros) sobre raça e } \\
\text { racismo em um contexto educacional de supremacia branca }\end{array}$ & $1 ; 9 ; 28 ; 36 ; 37 ; 38 ; 50$ & 7 \\
\hline 9 - Organizações estudantis no desenvolvimento de identidades negras & 29; & 1 \\
\hline 10 - Tendência ao embranquecimento na classificação de raça em pesquisas & 41 & 1 \\
\hline
\end{tabular}

Fonte: Elaborado pelas autoras.

A seguir descreveremos pontos de destaque em cada categoria, os quais indicam aspectos essenciais dos artigos da amostra, de modo a apresentar a essência do conjunto de dados.

$\mathrm{Na}$ categoria 1, os textos apresentam como as diferenças raciais e, por conseguinte, demográficas e econômicas, afetam o desempenho dos estudantes, assim como a sua saúde mental e sua relação com os docentes. Como aspectos relevantes apontados nessa categoria, pode-se mencionar que os textos discutem: 1) a relação entre educação e riqueza; e 2) como as diferenças raciais, a pobreza e os estereótipos influenciam no desempenho, permanência, autoestima e saúde mental dos alunos negros em relação aos brancos.

Nessa categoria, o estudo de Logan et al. (2012) documenta a extensão das desigualdades no desempenho escolar entre escolas frequentadas por crianças de diferentes origens raciais e étnicas, destacando aspectos segregadores, como raça, pobreza e localização metropolitana, que afetam severamente o desempenho dos alunos negros. Tal achado é corroborado por Oliveira e Oliveira (2015), os quais afirmam que o acesso às oportunidades é determinado pelas diferenças étnico-raciais, baseando-se na superioridade das pessoas brancas, que são direta ou indiretamente beneficiadas em todos os lugares e posições devido à segregação da população negra.

McGee e Martin (2011) apontam que estudantes negros sofrem discriminação por causa de estereótipos, o que consequentemente piora o racismo. Nesse contexto, o número de estudantes negros em relação ao de estudantes brancos é menor no ensino médio (Gregory et al., 2011). Ou seja, as relações raciais afetam a permanência nas escolas e os resultados são desproporcionais entre estudantes negros e brancos (Gregory et al., 2010).

Nesse sentido, Nogueira e Silva (2016), analisando os dados do ensino médio a partir dos dados da Pesquisa Nacional por Amostra de Domicílio (Pnad) nos anos de 2003 a 2013, afirmam que indicadores apontam a persistência de desigualdade entre brancos e negros nessa etapa de ensino. O mesmo aspecto é apontado em um estudo mais recente de Rodrigues et al. (2021) que analisa os dados da Pnad até 2018. Em outras palavras, as desigualdades raciais foram mantidas, o que reforça as teses sobre como as formas de discriminação e racismo no interior da escola dificultam o sucesso do alunado negro.

$\mathrm{Na}$ categoria 2, a TRC é utilizada para analisar raça, racismo, práticas pedagógicas, aspectos sociais e microagressões. Nessa categoria, as discussões destacam os efeitos do racismo, do desrespeito cultural e das microagressões. Ademais, sob o enfoque da TRC, os autores apontam que tais práticas excluem os indivíduos afetados do contexto educacional e social, causando insegurança, frustração e isolamento (Solorzano et al., 2000). Também são apresentados os benefícios e limitações da TRC 
em torno da discussão sobre raça e racismo (Abrams \& Moio, 2009).

Desse modo, como já apontado na discussão da Figura 5, destaca-se a TRC como uma importante ferramenta intelectual e social utilizada há anos para a desconstrução, reconstrução e construção tanto de estruturas quanto de discursos opressivos (Ladson-Billings, 1998). Como também apontado por Ferreira (2014), a TRC tem contribuído para discutir as relações raciais, raça, racismo e estudos raciais críticos na área da educação, da sociologia, da antropologia e da identidade racial, promovendo o avanço das discussões, bem como provocando mudanças significativas no contexto educacional.

A categoria 3 apresenta textos que discutem como as políticas educacionais melhoram a educação e as relações raciais. Os autores revelam que as reformas e políticas educacionais podem contribuir para a discussão da superioridade branca e a melhoria das condições de acesso e permanência dos negros na educação (McGuinn, 2012; Buras, 2011). Como destaque na categoria, o trabalho de Buras (2011) aponta, em suas conclusões, que a pesquisa crítica e o ativismo contínuo são cruciais na Erer. A autora afirma ainda que princípios democráticos devem orientar as ações governamentais na educação, sendo o primeiro deles garantir escolas públicas baseadas na vizinhança, as quais apoiem a restauração de comunidades oprimidas racial e economicamente, com acesso aberto e inclusivo, sem barreiras formais ou informais à matrícula e à retenção de estudantes.

Apesar da resistência, as políticas públicas educacionais são fundamentais para a promoção de uma efetiva igualdade racial, pois promovem a superação das inaceitáveis distâncias que ainda hoje separam, afetam e determinam as vidas dos brancos e negros (Katrib \& Silva, 2020). Tal aspecto também foi pontuado nos tópicos de tendência da Figura 5, revelando que, além de as pesquisas relacionadas a ações e políticas afirmativas serem frequentes, também estão entre aquelas de maior impacto em termos de citação na área.

$\mathrm{Na}$ categoria 4, que concentra o maior número de textos, discute-se como a formação de professores pode melhorar a valorização da diversidade e as relações raciais. Pode-se notar uma clara preocupação quanto à falta de formação adequada dos docentes para trabalhar as relações raciais, assim como a importância de uma atitude correta por parte dos professores, visto que sua postura pode agravar as situações de racismo e, consequentemente, o fracasso dos alunos (Picower, 2009; Cooper, 2009).

Como destaque, a pesquisa de Cooper (2009) aponta que os docentes podem ser agentes sociais transformadores quando preparados para mediar um ensino que promova a valorização da diversidade cultural e racial. Corroborando o exposto, Ladson-Billings (2000) e Merryfield (2000) apontam a falta não apenas de disciplinas na formação inicial dos docentes mas também de cursos de formação continuada na área como uma das razões pelas quais os afro-americanos ainda enfrentam exclusão, abandono e racismo no contexto escolar. Tal aspecto foi também observado no Brasil em estudos mais recentes (Eugênio \& Santana, 2018; Silva \& Marques, 2015; Alves, 2017; Lírio, 2015).

Nos artigos da categoria, há uma clara denúncia dos efeitos do silenciamento dos docentes frente às ações de racismo na escola, sendo tal silenciamento um agravante a dificultar a permanência e o êxito de estudantes negros. O estudo de Cochran-Smith (2000), por exemplo, aponta a necessidade de transformar suposições racistas profundamente enraizadas, destacando que ensinar lições sobre raça e racismo para professores é uma forma de desaprender o racismo.

Assim, a formação é apontada pelos pesquisadores como uma necessidade para o trabalho com a diversidade, e são apresentados resultados positivos da aplicação de cursos. Tal achado é corroborado por Tivane (2019), que trouxe resultados positivos de um curso de formação, tendo em vista que os participantes das atividades e projetos aplicados tiveram suas identidades e subjetividades transformadas, resultado de um trabalho com questões sobre identidades, diversidade, preconceito e racismo. Uma das alternativas para o trabalho de valorização 
da diversidade foi também mostrada por meio de um curso de formação de professores que utilizou a literatura como forma de trabalhar a diversidade e interrogar suposições racistas presentes nos cursos e nos currículos (Cochran-Smith, 2000).

A formação docente na Erer é de extrema importância e precisa ser explorada e fomentada nas pesquisas, haja vista que o cenário educacional apresenta que a maioria dos professores não estão preparados para desenvolver uma educação que respeite a diversidade; por isso é preciso dar uma maior atenção à temática, uma vez que o espaço da sala de aula é extremamente propício para o reconhecimento do racismo (Gillam, 2016; Pereira et al., 2018).

De acordo com o número de textos das categorias, a temática da formação de professores é a mais recorrente nos artigos mais citados nos últimos 20 anos. A atenção dos pesquisadores para a área nos leva à importante reflexão sobre quão essencial é a formação de professores para o desenvolvimento de uma educação que respeite a diversidade e a melhoria das relações raciais no contexto escolar.

$\mathrm{Na}$ categoria 5, os textos discutem como o reconhecimento da diversidade racial e cultural melhora o desempenho e o engajamento dos estudantes negros. Os estudos apontam que a valorização da diversidade, a socialização cultural e o conhecimento histórico no contexto escolar melhoram a autoestima, assim como o desenvolvimento cognitivo e comportamental de estudantes negros (Bowman, 2010, 2011; Hughes et al., 2009). Desse modo, destaca-se a importância de uma educação crítica, multicultural e focada em questões raciais, de modo a garantir a equidade na educação.

Desse modo, o reconhecimento da diversidade conduz à proteção das culturas minoritárias, enquanto uma postura contrária só pode levar à guerra das culturas (Munanga, 2010). Por isso, a discussão sobre o multiculturalismo deve levar em conta os temas da identidade racial e da diversidade cultural para a formação da cidadania (Torres, 2001), pois, em um mundo pluralista, as relações entre democracia, cidadania e educação não podem ser tratadas sem se considerar o multiculturalismo (Munanga, 2010).

$\mathrm{Na}$ categoria 6, o estudo discute a naturalização do preconceito e falta de diálogo sobre as relações raciais, mostrando o confronto em torno da raça branca, que naturaliza a violência causada pelo preconceito de cor nas escolas (Leonardo \& Porter, 2010).

O racismo naturalizado e incorporado na sociedade caracteriza um racismo estrutural, na medida em que é construído nas relações históricas e sociais (Almeida, 2019). Ou seja, as práticas, hábitos e costumes racistas estão incorporados aos valores da sociedade e introduzidos no cotidiano, de modo que se manifestam através do tratamento desigual dos seres humanos, acabando por piorar os índices de violência e segregação (Goss \& Salles, 2020).

$\mathrm{Na}$ categoria 7, o estudo destaca a importância das HBCU para a formação dos alunos negros, capacitando-os e encorajando-os a superar suas fraquezas quando os outros estabelecimentos de ensino superior restringiram sua participação (Gasman \& Palmer 2008). Assim, o acesso da população negra à universidade, mesmo apresentando inúmeros desafios quanto à permanência e ao êxito acadêmico, é considerado como a possibilidade de os jovens negros fortalecerem seu pertencimento étnico-racial em um contexto historicamente homogêneo (Marques, 2018).

O foco da categoria 8 é a representação e a postura de professores (brancos e negros) sobre raça e racismo em um contexto educacional de supremacia branca. Os estudos investigam como professores brancos abordam questões de raça e racismo, destacando que professores brancos têm uma expectativa menor em relação à escolaridade dos alunos negros e as expectativas dos alunos negros são maiores quando os docentes são negros (Haviland, 2008; Goldsmith, 2004). Mostram a sub-representação e o baixo status acadêmico dos professores afro-americanos e destacam que, quando os professores reagem ao racismo, os resultados são positivos para os alunos negros (Verkuyten \& Thijs, 2002; Allen et al., 2000). 
A esse respeito, é importante ressaltar o quanto a postura docente em silenciar-se frente ao preconceito racial exposto sinaliza ao estudante discriminado que ele não pode contar com a cooperação de seu professor (Santiago, 2015). Nesse sentido, a prática do professor pode contribuir para a superação de discursos e ideologias racistas, indo contra o que é posto como normal e natural na sociedade e disseminando novos conceitos, o que contribui para a desconstrução do racismo (Tuono \& Vaz, 2017). Tal fato, mais uma vez, retoma a importância do investimento e da atenção voltada para a formação inicial e continuada de docentes com foco na Erer.

$\mathrm{Na}$ categoria 9, o estudo destaca a importância das organizações estudantis no desenvolvimento de identidades negras, promovendo envolvimento de estudantes de grupos minoritários e contribuindo para a expressão e desenvolvimento de suas identidades (Harper \& Quaye, 2007). Visto que é na experiência coletiva, em sociedade, que as identidades são produzidas, a escola é um dos lugares fundamentais para a construção da identidade do indivíduo desde a infância. Porém o racismo e o preconceito na escola posicionam o cidadão negro como de "segunda classe", decorrendo disso o desenvolvimento de uma identidade articulada em torno de valores considerados socialmente negativos (Ferreira \& Camargo, 2011).

Por fim, na categoria 10, o estudo mostra uma análise nacional, revelando as inconsistências entre a classificação de entrevistadores e respondentes com relação à raça (Telles, 2002). Isso porque, pela análise dos dados, foi possível perceber que os entrevistadores "embranqueceram" pessoas com nível superior que se identificaram como pardas, principalmente nas regiões em quehá maior percentual de pessoas não brancas na população. Assim, os dados do levantamento de aproximadamente 5 mil moradores de várias regiões do Brasil confirmaram a ocorrência da associação entre a escolaridade e o "branqueamento" das respostas. Dessa forma, retomamos o conceito da pigmentocracia, o qual se faz presente no processo de embranquecimento e segregação dos negros e negras, fomentando o branqueamento e a negação da identidade negra. Muitas vezes, a ascensão social dos negros torna-se um motivo para embranquecê-los, afastando-os de sua identificação com sua descendência negra. Nesse sentido, faz-se necessário a resistência de negros e negras, ao denunciarem o colorismo, o embranquecimento e o racismo estrutural presente na sociedade (Cruz \& Martins, 2017).

Ao nos afastarmos do panorama exposto pelas categorias, podemos visualizar melhor alguns tópicos de impacto destacados ao longo dos anos. A relevância da discussão sobre a formação docente está presente em vários momentos, assim como os impactos do racismo na evasão escolar e no desempenho dos estudantes (Cordeiro, 2010; Silva, 2019). As discussões sobre raça e etnia na perspectiva da TRC também constam de muitos trabalhos e direcionam para novos tópicos de tendência nas últimas décadas, tais como as políticas de ações afirmativas e a educação multicultural (Gasman \& Palmer, 2008; Milner Iv, 2008; Ready \& Wright, 2011; McGee \& Martin, 2011). As microagressões e a naturalização da violência, embora apareçam em menos trabalhos, também são evidenciadas tanto em pesquisas mais antigas quanto em artigos mais recentes, apontando os efeitos do racismo, muitas vezes velado e negado, na vida daqueles que enfrentam diariamente a luta por oportunidades de vida mais justas (Gershenson et al., 2016; Huber \& Solorzano, 2015; Logan et al., 2012).

\section{Considerações finais}

O aumento recente no número de publicações, países e pesquisadores envolvidos no estudo das relações étnico raciais fornece subsídios para afirmar a melhoria da qualidade da pesquisa nessa área. Tal aspecto gera maior facilidade de acesso à literatura científica de qualidade sobre a Erer. Esse quadro refere-se a múltiplos contextos de um todo histórico, envolvendo: o chamamento internacional caracterizado pelas ações da ONU, a criação de Programas de 
Pós-Graduação em Educação; assim como a evolução da pesquisa científica, considerando bases de dados como ferramentas para fundamentar análises em Educação. Destaca-se neste estudo a importância da sistematização das publicações na área da Erer, a fim de que se promova a divulgação das pesquisas nessa área de fundamental importância para os professores.

Em nossa análise, foram encontrados 2.916 artigos publicados em 384 fontes ao longo de 62 anos considerados na pesquisa. O crescimento anual das pesquisas na área é de 7,43\% e mais de $90 \%$ da produção está concentrada após 1990.

Os 10 países que mais publicaram foram: Estados Unidos, Inglaterra, Canadá, Brasil, África do Sul, Austrália, Espanha, Nova Zelândia Bélgica e Noruega. O Brasil se destaca entre os 10 países com maior número de publicações na área. Nos últimos cinco anos, os tópicos mais recorrentes nas publicações giram em torno das ações afirmativas, imigração, educação multicultural e discriminação.

A maior rede de colaboração de autores é composta por John F. Dovidio, Burke, Phelan, Van Ryn, Perry e Hardeman. A maior rede de cocitação está em torno do trabalho de Ladson-Billings e Tate (1995), um clássico que apresentou a TRC para a comunidade de pesquisadores da educação.

Quanto à análise de conteúdo dos 50 artigos mais citados dos últimos 20 anos, na interpretação dos dados da categorização destaca-se que as temáticas mais discutidas estão concentradas nas categorias 4 e 1 , ou seja, a temática da formação de professores para o desenvolvimento da Erer e a temática que discute a interferência das diferenças raciais e como elas afetam o desempenho dos negros no contexto educacional.

As categorias 2, 5 e 8 também têm um número representativo de textos e discutem a TRC, a importância do reconhecimento da diversidade racial e cultural e o posicionamento dos professores sobre conceitos de raça e racismo. Temáticas como as políticas educacionais, naturalização e falta de discussão sobre o racismo, a importância das HBCU e das organizações estudantis e tendência ao embranquecimento nas pesquisas também são discutidas.

É evidente a necessidade de pesquisas com a temática das relações étnico-raciais, bem como a divulgação dos estudos já realizados, visto que as relações raciais ainda se encontram em um território de tensões e conflitos. Atualmente, nos últimos cinco anos, os tópicos mais recorrentes nas publicações giram em torno das ações afirmativas, imigração, uma educação multicultural e os efeitos da discriminação, como pôde ser observado pela exposição da evolução temática da pesquisa no campo. O contexto apresentado nas produções afeta diretamente a proposição de políticas públicas na área educacional, e por isso os conflitos raciais na educação precisam continuar no foco das discussões para a melhoria do sistema educacional. Também é certo que a escola é um ambiente propício para desenraizar preconceitos e construir novos conceitos baseados na valorização da diversidade e respeito às diferenças étnico-raciais.

Como visto nesta revisão, podemos inferir que, de acordo com o número de textos, a temática da formação de professores é a mais recorrente nos artigos mais citados nos últimos 20 anos. Desse modo, pode-se perceber a grande importância da formação docente para o desenvolvimento de uma educação que respeite a diversidade e a melhoria das relações raciais no contexto escolar.

Como perspectivas futuras, pretende-se analisar com maior profundidade publicações relacionadas à formação de professores para a Erer, bem como aprofundar-se na discussão sobre a evolução da pesquisa no campo das relações étnico-raciais.

É importante reconhecer que a abordagem bibliométrica usada neste estudo, sem dúvida, possui limitações e pode excluir periódicos, publicações e pesquisadores que atuam na área. No entanto, o objetivo deste artigo foi oferecer uma descrição geral da evolução e do estado atual do campo. Portanto, a omissão de publicações pontuais não deve alterar significativamente o quadro mais amplo que se pretendeu ilustrar por meio da pesquisa. Ademais, para minimizar os efeitos dessa limitação, utilizou-se uma base de dados ampla, que levasse em consideração o campo da pesquisa educacional em suas categorias. 


\section{Referências}

Abrams, L. S., \& Moio, J. A. (2009). Critical race theory and the cultural competence dilemma in social work education. Journal of Social Work Education, 45(2), 245-261.

Abramowicz, A., \& Rodrigues, T. C. (2014). Descolonizando as pesquisas com crianças e três obstáculos. Educação \& Sociedade, 35(127), 461-474.

Allen, W. R., Epps, E. G., Guillory, E. A., Suh, S. A., \& Bonous-Hammarth, M. (2000). The Black academic: Faculty status among African Americans in U.S. higher education. Journal of Negro Education, 69(1-2), 112-127.

Almeida, S. (2019). Racismo estrutural. Pólen.

Alves, M. M. (2017). Lei 10.639/03, formação docente e NEABs: A democratização do currículo como um desafio para a educação brasileira. Cadernos do Aplicação, 30(1-2), 33-47.

Aria, M., \& Curccurullo, C. (2017). Bibliometrix: An R-tool for comprehensive science mapping analysis. Journal of Informetrics, 11(4), 959-975.

Arroyo, M. G. (2010). Políticas educacionais e desigualdades: A procura de novos significados. Educação \& Sociedade, 31(113), 1381-1416.

Bardin, L. (2011). Análise de conteúdo (4a ed.) Edições70.

Benner, A. D., \& Crosnoe, R. (2011). The racial/ethnic composition of elementary schools and young children's academic and socioemotional functioning. American Educational Research Journal, 48(3), 621-646.

Bonilla-Silva, E. (2004). From bi-racial to tri-racial: Towards a new system of racial stratification in the USA. Ethnic and Racial Studies, 27(6), 931-950.

Booth, T., \& Ainscow, M. (2011). The index for inclusion: Developing learning and participation in schools. CSIE.

Bowman, N. A. (2010). College diversity experiences and cognitive development: A meta-analysis. Review of Educational Research, 80(1), 4-33.

Bowman, N. A. (2011). Promoting participation in a diverse democracy: A meta-analysis of college diversity experiences and civic engagement. Review of Educational Research, 81(1), 29-68.

Buras, K. L. (2011). Race, charter schools, and conscious capitalism: On the spatial politics of whiteness as property (and the unconscionable assault on black New Orleans). Harvard Educational Review, 81(2), 296-331.

Brittian, A. S., Kim, S. Y., Armenta, B. E., Lee, R. M., Umaña-Taylor, A. J., Schwartz, S. J., Villalta, I. K., Zamboanga, B. L., Weisskirch, R. S., Juang, L. P., Castillo, L. G., \& Hudson, M. L. (2015).

Do dimensions of ethnic identity mediate the association between perceived ethnic group discrimination and depressive symptoms? Cultural Diversity and Ethnic Minority Psychology, 21(1), 41-53.

Candau, V. M. F. (2011). Diferenças culturais, interculturalidade e educação em direitos humanos. Educação \& Sociedade, 32(117), 1087-1103.

Canen, A. (2007). O multiculturalismo e seus dilemas: Implicações na educação. Comunicação e Política, 25(2), 91-107.

Carvalho, M. J. L. (2014). Segregação residencial e discriminação étnica na área metropolitana de Lisboa: O olhar das crianças. Educação \& Sociedade, 35(128), 629-996.

Case, K. A., \& Hemmings, A. (2005). Distancing strategies: White women preservice teachers and antiracist curriculum. Urban education, 40(6), 606-626.

Clève, C. M. (2016). Ações afirmativas, justiça e igualdade. Revista Digital de Direito Administrativo, 3(3), 542-557.

Cochran-Smith, M. (2000). Blind vision: Unlearning racism in teacher education. Harvard Educational Review, 70(2), 157-190. 
Coelho, W. N. B., \& Soares, N. J. B. (2017). Formação continuada de professores: As ações da universidade e a Lei n. 10.639/2003. Cadernos de Pesquisa: Pensamento Educacional, 12(31), 141-156.

Constantine, M. G., \& Blackmon, S. M. (2002). Black adolescents' racial socialization experiences: Their relations to home, school, and peer self-esteem. Journal of Black Studies, 32(3), 322-335.

Cooper, C. W. (2009). Performing cultural work in demographically changing schools: Implications for expanding transformative leadership frameworks. Educational Administration Quarterly, 45(5), 694-724.

Cordeiro, M. J. J. A. (2010). Ações afirmativas: Políticas de acesso e permanência nas instituições de ensino superior. Revista Politica \& Trabalho, (33), 97-115.

Creswell, J.W., \& Plano Clark, V. L. (2011). Designing and conducting mixed methods research (2a ed.). Sage Publications.

Cruz, J. T., \& Martins, P. (2017). Colorismo e embranquecimento nas falas de vlogueiras negras. VI Seminário de Extensão, Ensino, Pesquisa e Inovação do IFPR, 1-24.

Delgado, R. (2001). Two ways to think about race: Reflections on the id, the ego, and other reformist theories of equal protection. Georgetown Law Journal, 1(89), 2279-2296.

Denson, N., \& Chang, M. (2009). Racial diversity matters: The impact of diversity-related student engagement and institutional context. American Educational Research Journal, 46(2), 322-353.

Dias, E. C., \& Cecatto, A. (2015). Entre teoria e prática: A formação docente e a apropriação da Lei 10.639/2003 no cotidiano escolar. História \& Ensino, 21(2), 283-306.

Dougherty, K. J., \& Kienzl, G. S. (2006). It's not enough to get through the open door: Inequalities by social background in transfer from community colleges to four-year colleges. Teachers College Record, 108(3), 452-487.

Epstein, T. (1998). Deconstructing differences in African-American and European-American adolescents' perspectives on US history. Curriculum Inquiry, 28(4), 397-423.

Eugênio, B. G., \& Santana, F. (2018). Relações étnico-raciais e o trabalho com a Lei 10.639/03: Análise de uma experiência com formação docente. Ensino \& Pesquisa, 16(1), 58-73.

Faedo, J. Y. Y., Yamamoto, V. S., \& Jesus-Lopes, J. C. (2017). Ações afirmativas no Brasil: Uma pesquisa bibliométrica. Desafio Online, 5(3), 384-402.

Farkas, G. (2003). Racial disparities and discrimination in education: What do we know, how do we know it, and what do we need to know?. Teachers College Record, 105(6), 1119-1146.

Ferreira, A. J. (2014). Teoria racial crítica e letramento racial crítico: Narrativas e contranarrativas de identidade racial de professores de línguas. Revista da ABPN, 6(14), 236-263.

Ferreira, R. F., \& Camargo, A. C. (2011). As relações cotidianas e a construção da identidade negra. Psicologia: Ciência e Profissão, 31, 374-389.

Fries-Britt, S., \& Turner, B. (2002). Uneven stories: Successful Black collegians at a Black and a White campus. The Review of Higher Education, 25(3), 315-330.

Gasman, M., \& Palmer, R. (2008). It takes a village to raise a child: The role of social capital in promoting academic success for African American men at a black College. Journal of College Student Development, 49(1), 52-70.

Gerhardt, T. E., \& Silveira, D. T. (Orgs.). (2009). Métodos de pesquisa. Editora UFRGS.

Gershenson, S., Holt, S. B., \& Papageorge, N. W. (2016). Who believes in me? The effect of student-teacher demographic match on teacher expectations. Economics of education review, 52, 209-224.

Gillam, R. (2016). Learning to transgress: Law 10.639 and teacher-training classrooms in São Paulo, Brazil. Transforming Anthropology, 24(1), 70-79.

Gillborn, D., Rollock, N., Vincent, C., \& Ball, S. (2012). 'You got a pass, so what more do you want?' Race, class and gender intersections in the educational experiences of the black middle class. Race Ethnicity and Education, 15(1), 121-139. 
Goldsmith, P. A. (2004). Schools racial mix, students optimism, and the black-white and latino-white achievement gaps. Sociology of Education, 77(2), 121-147.

Gomes, J. B. B. (2001). A recepção do instituto da ação afirmativa pelo direito constitucional brasileiro. Revista de Informação Legislativa, 38(151), 129-152.

Gomes, N. L. (2012). Relações étnico-raciais, educação e descolonização dos currículos. Currículo sem Fronteiras, 12(1), 98-109.

Gomes, N. L., \& Jesus, R. E. (2013). As práticas pedagógicas de trabalho com relações étnico-raciais na escola na perspectiva de Lei 10.639/2003: Desafios para a política educacional e indagações para a pesquisa. Educar em Revista, 29(47), 19-33.

Gomes, N. L., \& Miranda, S. A. (2018). Dossiê: Educação na Década Internacional dos Afrodescendentes (2015-2024). Educação em Revista, 34, 1-4.

Goss, C. C., \& Salles, N. A.Fo. (2020). Epistemologias do Sul em contraste a naturalização do racismo estrutural: Combate a sociedade desigual. Revista SURES, 1(14), 126-141.

Gregory, A., Cornell, D., \& Fan, X. (2011). The relationship of school structure and support to suspension rates for black and white high school students. American Educational Research Journal, 48(4), 904-934.

Gregory, A., Skiba, R. J., \& Noguera, P. A. (2010). The achievement gap and the discipline gap: Two sides of the same coin? Educational Researcher, 39(1), 59-68.

Guimarães, S. (2015). The teaching of Afro-Brazilian and indigenous culture and history in Brazilian basic education in the 21st century. Policy Futures in Education, 13(8), 939-948.

Gutiérrez, R. (2013). The sociopolitical turn in mathematics education. Journal for Research in Mathematics Education, 44(1), 37-68.

Harper, S. R. (2012). Race without racism: How higher education researchers minimize racist institutional norms. The Review of Higher Education, 36(1), 9-29.

Harper, S. R., \& Quaye, S. J. (2007). Student organizations as venues for black identity expression and development among African American male student leaders. Journal of College Student Development, 48(2), 127-144.

Haviland, V. S. (2008). “Things get glossed over”: Rearticulating the silencing power of whiteness in education. Journal of Teacher Education, 59(1), 40-54.

Hernández-Torrano, D., Somerton, M., \& Helmer, J. (2020). Mapping research on inclusive education since Salamanca Statement: A bibliometric review of the literature over 25 years. International Journal of Inclusive Education, 24, 1-20.

Huang, C., Yang, C., Wang, S., Wu, W., Su, J., \& Liang, C. (2019). Evolution of topics in education research: A systematic review using bibliometric analysis. Educational Review, 72(3), 1-17.

Huber, L. P., \& Solorzano, D. G. (2015). Racial microaggressions as a tool for critical race research. Race Ethnicity and Education, 18(3), 297-320.

Hughes, D., Witherspoon, D., Rivas-Drake, D., \& West-Bey, N. (2009). Received ethnic-racial socialization messages and youths' academic and behavioral outcomes: Examining the mediating role of ethnic identity and self-esteem. Cultural Diversity \& Ethnic Minority Psychology, 15(2), 112-124.

Instituto Nacional de Estudos e Pesquisas Educacionais Anísio Teixeira. (2020). Thesaurus Brasileiro da Educação. https://tinyurl.com/vtzm2fe8

Johnson, L. (2002). "My eyes have been opened”: White teachers and racial awareness. Journal of Teacher Education, 53(2), 153-167.

Katrib, C. M. I., \& Silva, A. F. da Jr.. (2020). Políticas educacionais de igualdade racial: concepções, reflexões e pluralidades. Revista Educação e Políticas em Debate, 9(3), 548-555.

Kohli, R., \& Solórzano, D. G. (2012). Teachers, please learn our names!: Racial microagressions and the K-12 classroom. Race Ethnicity and Education, 15(4), 441-462. 
Ladson-Billings, G. (1998). Just what is critical race theory and what's it doing in a nice field like education? Qualitative Studies in Education, 11(1), 7-24.

Ladson-Billings, G. (2000). Fighting for our lives: preparing teachers to teach African American students. Journal of Teacher Education, 51(3), 206-214.

Ladson-Billings, G., \& Tate, W. F. (1995). Toward a critical race theory of education. Teachers College Record, 97(1), 47-68.

Lawlor, J., Mills, K., Neal, Z., Neal, J. W., Wilson, C., \& Mcalindon, K. (2019). Approaches to measuring use of research evidence in K-12 settings: A systematic review. Educational Research Review, 27, 218-228.

Leonardo, Z., \& Porter, R. K. (2010). Pedagogy of fear: Toward a Fanonian theory of 'safety' in race dialogue. Race Ethnicity and Education, 13(2), 139-157.

Lewis, A. E. (2001). There is no "race" in the schoolyard: Color-blind ideology in an (almost) all-white school. American Educational Research Journal, 38(4), 781-811.

Lírio, C. J. (2015). Alegações sobre mídia digital no âmbito da lei federal 10.639/2003, consciência linguística crítica e formação docente. Muitas Vozes, 4(1), 11-25.

Logan, J. R., Minca, E., \& Adar, S. (2012). The geography of inequality: Why separate means unequal in american public schools. Sociology of Education, 85(10), 1-21.

Marques, E. P. S. (2017). A implementação da lei 10.639/2003 no estado de Mato Grosso do Sul e a formação continuada de professores: Uma perspectiva emancipatória e decolonial. Revista Contemporânea de Educação, 12(23), 51-68.

Marques, E. P. S. (2018). O acesso à educação superior e o fortalecimento da identidade negra. Revista Brasileira de Educação, 23, 1-23.

McGee, E. O., \& Martin, D. B. (2011). You would not believe what I have to go through to prove my intellectual value! Stereotype management among academically successful black mathematics and engineering students. American Educational Research Journal, 48(6), 1347-1389.

McGuinn, P. (2012). Stimulating reform: Race to the top, competitive grants and the Obama Education Agenda. Educational Policy, 26(1), 136-159.

Merryfield, M. (2000). Why aren't teachers being prepared to teach for diversity, equity, and global interconnectedness? A study of lived experiences in the making of multicultural and global educators. Teaching and Teacher Education, 16(4), 429-443.

Milner Iv, H. R. (2008). Critical race theory and interest convergence as analytic tools in teacher education policies and practices. Journal of teacher education, 59(4), 332-346.

Moreira, A. F. B., \& Candau, V. M. (2008). Multiculturalismo: Diferenças culturais e práticas pedagógicas. Vozes.

Munanga, K. (2010). Educação e diversidade cultural. Cadernos Penesb, 10, 37-54.

Müller, T. M. P., \& Coelho, W. N. B. (2013). A Lei no 10.639/03 e a formação de professores: Trajetória e perspectivas. Revista da Associação Brasileira de Pesquisadores/as Negros/as (ABPN), 5(11), 29-54.

Nogueira, K. K. O., \& Silva, P. V. B. (2016). Análise de desigualdades educacionais entre negros e brancos nas PNADS 2003 a 2013, no Ensino Médio, Região Metropolitana de Curitiba. InterMeio: Revista do Programa de Pós-Graduação em Educação, 22(42/44), 29-48.

Novaes, E. C., Nonato, E. M. N., Souza Xavier, J. M., \& Lima, L. S. P. (2020). “A carne mais barata do mercado (acadêmico) é a carne negra”: O estado da arte sobre o diálogo entre as relações raciais e a educação em periódicos brasileiros de educação. Pró-Discente, 26(1), 30-49.

Oliveira, R. J., \& Oliveira, R. M. S. (2015). Origens da segregação racial no Brasil. Amérique Latine Histoire et Mémoire. Les Cabiers ALHIM, (29). https://tinyurl.com/pc6dxdvm

Omi, M., \& Winant, H. (1994). Racial formation in the United States (2a ed.). Routledge. 
Onyeador, I. N., Wittlin, N. M., Burke, S. E., Dovidio, J. F., Perry, S. P., Hardeman, R. R., Dyrbye, L. N., Herrin, J., Phelan, S. M., \& Van Ryn, M. (2019). The value of interracial contact for reducing anti-black bias among non-black physicians: a Cognitive Habits and Growth Evaluation (CHANGE) Study Report. Psychological Science, 31(1), 18-30.

Organização das Nações Unidas para a Educação, a Ciência e a Cultura. (2006). Guidelines on Intercultural Education. https://tinyurl.com/zpxckzc

Organização das Nações Unidas para a Educação, a Ciência e a Cultura. (2020). Unesco Thesaurus. https:// tinyurl.com $/ 3 \mathrm{kyr} 6 \mathrm{bht}$

Passos, J. C. (2015). Relações raciais, cultura acadêmica e tensionamentos após ações afirmativas. Educação em Revista, 31, 155-182.

Paula, B. X., \& Guimarães, S. (2014). 10 anos da Lei Federal no 10.639/2003 e a formação de professores: Uma leitura de pesquisas científicas. Educação e Pesquisa, 40(2), 435-448.

Pereira, A. S. M., Gomes, D. P., Carmo, K. T., \& Silva, E. V. M. (2018). Aplicação das leis 10.639/03 e 11.645/08 nas aulas de educação física: Diagnóstico da rede municipal de Fortaleza/CE. Revista Brasileira de Ciências do Esporte, 41(4), 1-7.

Phelan, S. M., Burke, S. E., Cunningham, B. A., Perry, S. P., Hardeman, R. R., Dovidio, J. F., Herrin, J., Dyrbye, L. N., White, R. O., YeazeL, M. W., Onyeador, I. N., Wittlin, N. M., Harden, K., \& Van Ryn, M. (2019). The effects of racism in medical education on students' decisions to practice in underserved or minority communities. Academic Medicine, 94(8), 1178-1189.

Picower, B. (2009). The unexamined whiteness of teaching: How white teachers maintain and enact dominant racial ideologies. Race Ethnicity and Education, 12(2), 197-215.

Rafols, I., Molas-Gallart, J., Chavarro, D. A., \& Robinson-Garcia, N. (2016). On the dominance of quantitative evaluation in "peripheral" countries: Auditing research with technologies of distance. Social Science Research Network, 1-22. https://tinyurl.com/t2b6kx2a

Ramos, M. Y. (2018). Internacionalização da pós-graduação no Brasil: Lógica e mecanismos. Educação e Pesquisa, 44, 1-22.

Ready, D. D., \& Wright, D. L. (2011). Accuracy and inaccuracy in teachers' perceptions of young children's cognitive abilities: The role of child background and classroom context. American Educational Research Journal, 48(2), 335-360.

Ribeiro, M. S. L., Nabout, J. C., Pinto, M. P., Moura, I. O., Melo, T. L., Costa, S. S., \& Rangel, T. F. L. V. B. (2007). Análise cienciométrica em ecologia de populações: Importância e tendências dos últimos 60 anos. Acta Scientiarum. Biological Sciences, 29(1), 39-47.

Rodrigues, L. A. M. S., Barbosa, M. L. O., \& Ribeiro, C. M. (2021). Documentos oficiais e legislações educacionais no combate às desigualdades raciais: Estudo com base na PNAD. Revista Eletrônica de Educą̧ão, 15, 1-30.

Rolón-Dow, R. (2005). Critical care: A color (full) analysis of care narratives in the schooling experiences of Puerto Rican girls. American Educational Research Journal, 42(1), 77-111.

Sacco, A. M., Paula Couto, M. C. P., \& Koller, S. H. (2016). Revisão sistemática de estudos da psicologia brasileira sobre preconceito racial. Temas em Psicologia, 24(1), 233-250.

Santiago, F. (2015). Gritos sem palavras: Resistências das crianças pequenininhas negras frente ao racismo. Educação em Revista, (31), 129-153.

Saporito, S., \& Sohoni, D. (2006). Coloring outside the lines: Racial segregation in public schools and their attendance boundaries. Sociology of Education, 79(2), 81-105.

Silva, P. V. B., Regis, K., \& Miranda, S. A. (2018). Sobre a pesquisa Educação e Relações Étnico-Raciais. Educação em Revista, 34(69), 9-16.

Silva, S. C. L. (2019). Formação docente para a implementação da Lei 10.639/03: Concepções em curso na rede municipal de São Paulo [Dissertação de Mestrado em Educação]. Universidade Federal de São Paulo. 
Silva, T. S. (2017). O colorismo e suas bases históricas discriminatórias. Direito UNIFACS-Debate Virtual, (201), 1-19.

Silva, W. S., \& Marques, E. P. S. (2015). Educação e relações étnico-raciais: a Lei 10.639/03, a formação docente e o espaço escolar. Horizontes, 33(2), 47-56.

Silvério, V. R. (2002). Ação afirmativa e o combate ao racismo institucional no Brasil. Cadernos de Pesquisa, $117(2), 219-246$.

Solorzano, D., Ceja, M., \& Yosso, T. (2000). Critical race theory, racial microaggressions, and campus racial climate: The experiences of African American College Students. Journal of Negro Education, 69(1/2), 60-73.

Spaull, N. (2013). Poverty \& privilege: Primary school inequality in South Africa. International Journal of Educational Development, 33(5), 436-447.

Stanley, C. A. (2006). Coloring the academic landscape: Faculty of color breaking the silence in predominantly White colleges and universities. American Educational Research Journal, 43(4), 701-736.

Sue, D. W., Lin, A. I., Torino, G. C., Capodilupo, C. M., \& Rivera, D. P. (2009). Racial microaggressions and difficult dialogues on race in the classroom. Cultural Diversity and Ethnic Minority Psychology, 15(2), 183.

Telles, E. E. (2002). Racial ambiguity among the brazilian population. Ethnic and Racial Studies, 25(3), 415-441.

Testa, J. (2015). The Thomson Reuters Journal Selection Process. Transnational Corporations Review, 1(4), 59-66.

Tivane, E. M. (2019). Africanidades no processo formativo de professores de matemática [Tese de Doutorado em Educação]. Universidade Federal de Uberlândia.

Torres, C. A. (2001). Democracia, educação e multiculturalismo. Vozes.

Tuono, N. E. F., Vaz, M. R. T. (2017). O racismo no contexto escolar e a prática docente. Debates em Educação, 9(18), 204-216.

Vaught, S. E., \& Castagno, A. E. (2008). “I don't think I'm a racist”: Critical Race Theory, teacher attitudes, and structural racism. Race Ethnicity and Education, 11(2), 95-113.

Verkuyten, M., \& Thijs, J. (2002). Racist victimization among children in The Netherlands: The effect of ethnic group and school. Ethnic and Racial Studies, 25(2), 310-331.

Vervaet, R., D’hondt, F., Van Houtte, M., \& Stevens, P. A. J. (2016). The ethnic prejudice of Flemish teachers: The role of ethnic school composition and of teachability. Cultural Diversity and Ethnic Minority Psychology, 22(4), 552-562.

Williams, D., \& Williams-Morris, R. (2000). Racism and mental health: The African American experience. Ethnicity \& Health, 5(3-4), 243-268.

Young, E. (2010). Challenges to conceptualizing and actualizing culturally relevant pedagogy: How viable is the theory in classroom practice? Journal of Teacher Education, 61(3), 248-260.

Zuberi, T. (2016). Teoria crítica da raça e da sociedade nos Estados Unidos. Cadernos do CEAS: Revista Critica de Humanidades, (238), 464-487.

\section{Nota sobre autoria}

Leandra A. M. S. Rodrigues: participação no levantamento dos dados, categorização dos dados, metodologia e revisão final. Mayara Lustosa de Oliveira Barbosa: participação no levantamento dos dados, levantamento de dados bibliométricos, participação na metodologia e revisão final. Cristiane Maria Ribeiro: participação no levantamento dos dados, na metodologia e revisão final. 


\section{Disponibilidade de dados}

Os dados subjacentes ao texto da pesquisa estão informados no artigo.

\section{Como citar este artigo}

Rodrigues, L. A. M. S., Barbosa, M. L. de O., \& Ribeiro, C. M. (2022). Mapeando a pesquisa em educação das relações étnico-raciais. Cadernos de Pesquisa, 52, Artigo e07753.

https://doi.org/10.1590/198053147753 